\title{
A Discussion About Power Relations and the Concept of Distributed Leadership in Higher Education Institutions
}

\author{
Fabio Bento* \\ Programme for Teacher Education Norwegian University of Science and Technology, Norway
}

\begin{abstract}
In a context of increasing pressure to deliver high quality teaching and research, the need for "good leadership" has been emphasized as strategically decisive within the sector. Nevertheless, the structure and character of higher education institutions have historically no given space for top-down leadership which is usually associated with managerialism. The concept of distributed leadership has been suggested as a response to new challenges posed towards higher education institutions based on the understanding that more hierarchical leadership practices are not well suited to global complexity and change. In academic environments, the idea of collegiality is strongly-rooted assuming a "first among equals" approach to leadership where authority of professional expertise, self regulation, academic freedom and autonomy are more present than positional power. As a recognition of both the challenges faced by higher education institutions in the globalized world, and of perceptions of leadership that have historically characterized universities, the concept of distributed leadership has been presented as a framework for understanding leadership and change in higher education. The main argument of this article is that with the emphasis on participation and mutual influence, the distributed concept has many common features with the traditional collegial model of leadership in higher education. However, the lack of focus on internal dynamics of power relations still seems to be a limitation of this concept.
\end{abstract}

Keywords: Collegiality, higher education leadership, innovation, management, managerialism, organizational change.

\section{INTRODUCTION}

This article discusses leadership in processes of organizational change in higher education institutions. The debate about policy reform in higher education institutions in western countries is characterized by the assumption that leadership is a decisive factor in organizational change in educational institutions. However, rather than trying to identify "what works", my goal here is to understand important aspects of leadership by discussing it in relation to complexities of organizational life in higher education. Factors such as changing funding patterns linked with pressures to diversify higher education institution's funding base, competition, internationalization as well as continuing demands to deliver outstanding teaching and research, have been identified by policy-makers as a context where leadership is a determinant aspect of higher education organizations. Nevertheless, the structure and character of higher education institutions have historically not given space for top-down leadership which is usually associated with managerialism. In academic environments, the idea of collegiality is strongly-rooted assuming a "first among equals" approach to leadership where authority of professional expertise, self regulation, academic freedom and autonomy are more present than positional power. Partly as recognition of both the challenges faced by higher education institutions in the globalized world, and of perceptions of leadership that have historically characterized universities, the concept of distributed leadership has been presented as a framework for understanding leadership and change in

*Address correspondence to this author at the Programme for Teacher Education Norwegian University of Science and Technology, Norway; Tel: +47 412767 99; Fax: +47 735910 12; E-mail: fabio.bento@plu.ntnu.no higher education. My goal here is to discuss this concept and its potential in making sense of current organizational changes in educational organizations. This article's rationale proceeds in reviewing traditional and emerging approaches to leadership and narrowing down this discussion to the specific case of higher education. Leadership and institutional change will be discussed with a focus on departmental leadership and power relations in universities. I build upon Simkins' [1] proposition that in the leadership debate "making sense of things" is at least as important as "seeking what works". The main argument here is that although distributed leadership has a discourse of collective participation and democracy, it is embedded in a context of change in power relations in higher education. I begin by demonstrating how the very concept of leadership is a contested one in the field of organizational studies.

\section{DEFINITIONS AND APPROACHES TO LEADER- SHIP}

I discuss here a shift in focus on approaches to leadership. However, this shift has not always been a linear process as a review of the leadership literature shows an evolving series of schools of thoughts that not necessarily resolved the questions raised by precedent schools but moved the discussion and attempted to address different aspects of leadership [2]. Grint [3] presents characteristics of leadership theory that make it difficult to reach a common definition of leadership. First, there is a lack of common understanding whether leadership derives from personal qualities of the leader or whether a leader facilitates followership through what he or she does. Second there is the discussion about position, i.e., whether leadership derives from formally allocated authority leader or from formal influence. Thirdly, there is no agreement on whether the 
leader exerts an intentional causal impact on follower's actions or their actions are determined by context or situation. As Yukl [4] suggests, most definitions of leadership put emphasis on the possibility of leadership by groups and by individuals and the role of leadership in structuring activities. Most definitions of leadership assume that there is a social influence process whereby intentional influence is exerted by one individual or a group, over other people. This process shapes the activities and relationships in a group or organization. There are also leadership definitions that focus more specifically on creative aspects of organizations and less on power relations. One example of that is the definition presented by Fineman, Sims \& Yannis [5, p. 85]: "leadership is imagining, willing and driving and thereby making something happen which was not going to happen otherwise". A brief review of the literature about leadership theory shows how these questions have historically been addressed in different ways. This review shows a process of shift in emphasis from individual leaders attributes to the perception of leadership as a property of social systems.

The Trait Theory approach that was dominant until the $1940 \mathrm{~s}$ was concerned in identifying characteristics of successful leaders assumed that leadership traits could be isolated and people with such characteristics could be selected and placed in leadership positions. This approach showed limitations as it became evident that no consistent traits could be identified and most research based on this theory were often inconclusive [6]. As limitations of the Trait Theory were recognized, the Behavioral School moved the focus from leaders' personal qualities to what leaders actually do and increased awareness with leadership development [7]. This approach to leadership which has attracted most attention from practising managers aimed at observing and categorizing leadership styles [6]. Although behavioral theories have played a role in helping managers to develop particular leadership behavior, it showed limited results in showing what constitutes effective leadership in dissimilar contexts. Thus, Contingency School in the 1960s rose from the understanding that no leadership style is appropriate for every individual leader in every situation: "instead, contingency-situational theories were developed to indicate that the style to be used is contingent upon such factors as the situation, the people, the task, the organization and other environmental variables" $[6$, p. 8].

The leadership approaches discussed so far described the leader as a directive figure whose personal traits or actions differentiates him or her from the rest of the people. However, since the 1980 s, leadership research has moved its focus towards the importance of leaders' relationship with followers and interdependency of roles: "no longer the hero or the solo leader but the team leader. Not the leader always out in front but the leader who has capacity to follow. Not the master, but the servant" [6]. This change in focus was accompanied by a stronger concern with the symbolic or institutional feature of organizations and leaders' role in the process of consolidation of shared values [2]. In this approach, the leader defines the organizational reality through a process of articulation of his vision and his sense of mission of the organization. The concept of transformational leadership, which is part of this approach, highlighted change and the role of leadership in envisioning and implementing transformation. Another central concept here is transactional leadership that puts emphasis on the relationship between leaders and followers focusing on a form of contract by which leaders reward and recognize in return for commitment or loyalty [6]. Together these perspectives emphasize the leader's role in embedding their organizations with a shared vision, empower others and promote high levels of commitment. The transactional and transformational perspectives certainly helped to produce a fairly large literature with a prescriptive and instrumental character to managers. Research conducted based on this approach to leadership focused primarily on the role of top managers and has been criticized for presenting often a heroic and visionary image and focusing almost exclusively on stories of success [7]. Distributed leadership is a new school of leadership thought that rose as a reaction to this charismatic and heroic vision by claiming for a less formalized model of leadership where the leader's role is dissociated from the organizational hierarchy.

\section{DISTRIBUTED LEADERSHIP}

Recent literature about the role of leadership in educational institutions claims that the idea of leadership as being context-related and dispersed among people represents a more constructive framework to understand such organizations. This claim assumes that the hope that transformation in educational universities is directed by outstanding visionary leaders have turned out to be unrealistic and unsustainable [8]. The concept of distributed leadership has been suggested in connection with a shift in paradigms in the study of leadership in organizational theory. Distributed leadership derives from the emerging view of leadership that contrasts with the traditional concept of leadership as described by Simkins [1, p. 12]. Table 1 illustrates the contrast between traditional and emerging views of leadership.

The conceptual distinction and/or separation between leadership and management has been a disputed topic in the debate about emergent views of leadership. My option is to regard leadership and management as conceptually different but also as interconnected. Initially, I accept the differentiation presented by Fineman et al. [5, p. 86]: "sometimes these two activities are not distinguishable, but leadership implies generating something, which management does not. Managing implies a position which gives you the legitimate right to work through others, which leading does not". However, studies about changing leadership in higher education institutions have demonstrated that this distinction is not easily observed and that leadership and management are intersected processes [9]. Thus, I opt here to regard leadership and management as different but complementary process which gives space to use both concepts in a swapping way and admitting the existence of blurred zones between these.

The distributed leadership approach has its origin more in the fields of sociology and political science than in more long-established management literature and focus on organizational culture and change to highlight the contextual nature of leadership. The concept has the collective as its main concern and moves from the analysis and development of individual leader qualities to an investigation of what 
Table 1. An Emerging View of Leadership [1, p. 12]

\begin{tabular}{|c|c|}
\hline \multicolumn{1}{|c|}{ The Traditional View of Leadership } & An Emerging View \\
\hline \hline Leadership resides in individuals & Leadership is a property of social systems \\
\hline Leadership is hierarchically based and linked to the office & Leadership can occur anywhere \\
\hline Leadership occurs when leaders do things to followers & The leadership management/ distinction is unhelpful \\
\hline Leadership is different from and more important than management & Anyone can be a leader \\
\hline Leaders are different & The context of leadership is crucial \\
\hline Leaders make a crucial difference to organizational performance & Leadership is one of many factors that may influence organizational performance \\
\hline Effective leadership is generalizable & Thes of mutual influence \\
\hline
\end{tabular}

constitutes appropriate leadership and leadership processes. However, distributed leadership does not deny the importance of the role of individuals in formal leadership positions but assumes that it is part of the issue rather than being the central unit of analysis. This approach that has also been referred to as "dispersed", "shared" or "collective" leadership argues that individuals at different levels of the organization can influence colleagues and the overall course of the organization. Although there are variations on the how distributed leadership is defined, it is possible to identify some main premises [10]:

1. Emerging property of a group or network of interacting individuals: this contrasts with the traditional view that assumes that leadership rises from the individual

2. Openness of the boundaries of leadership: it wides up the conventional group of leaders, therefore raising the question of what groups or individuals contribute to leadership

3. Varieties of expertise are distributed across the many, not the few: it is related with openness of the boundaries, it assumes that different capabilities and perspectives can be found in individuals in the organization.

According to Simkins [1, p. 17], the main limitation of the traditional model when applied to higher education institutions is that "it gives undue emphasis to the formal authority delegated from above on the basis of position, whereas the authority in professional organizations typically depends on a much more complex range of factors, not least perceptions held by professional colleagues of the expertise and performance exhibited by those holding the roles". Hence, the concept offers strongly representation of leadership tailored to complex, changing and inter-dependent environments. However, two questions remain and permeate this study. First, although distributed leadership presents a compelling post-heroic view of leadership, to what extent is it really attainable in practice? Second, what is the contribution of distributed leadership for the understanding of organizational changes in higher education institutions? Thus, we move the discussion now towards universities' changing structures and systems.

\section{TRANSFORMATIONS IN HIGHER EDUCATION}

Organizational changes in higher education have occurred primarily as reactions to changes in the environments rather than by internal motivations. As Bargh, Scott, and Smith [11] claim, university leadership and management are linked with state-university relations. Competition, internationalization and quality assurance also play a role here. However, there are differences in the ways universities respond to changes in the surrounding environment as an assessment of the literature suggests a range of organizational cultures. One reason for this variation is related with a set of factors dealing with organizational identity such as institution's age, size, disciplinary mix and physical location. It is also fair to expect that the balance between teaching and research that differs among institutions affect their organizational structures. The first temptation to those formulating or trying to understand universities policy seems to be to identify examples of success and consistent organizational patterns among them. However, there is still relatively little research into academic organizations which succeed in clearly identifying transferable successful strategies. As Shattock [12] notices, it is rare that organizational change in higher education is driven by educational ideas rather than fashionable ideas deriving from the industry and the public sector or coherent thought about organizational fit. As the same author describes, organizational change has been to a large extent based on untested ideas about management. During the last two decades in most western countries, pressures exerted with the stagnation of public resources led to organization change in higher education institutions being associated with strategies aiming at securing accountability, best allocating resources, controlling costs and eliminating deficits.

Here, McNay's model [13] of internal culture embedded in four different quadrants is used to understand different styles of policy definition and control of implementation. This conceptual distinguishes four organizational types that vary on two dimensions: the degree of definition of policy and the degree of control of implementation. Collegial cultures are characterized by freedom to pursue university and personal goals unaffected by external control. Standards are set by the international disciplinary scholarly community and evaluation is by peer review. Decision-making is consensual, management style permissive [9]. Leadership assumes here a "first among equals" style and authority of professional power is more present than authority based on positional power. Academic autonomy and self-regulations are among fundamental principles here. Decision-making usually takes place in the form of consensual processes 
including debates and discussion within university committees. In collegial culture, organizational change is expected to happen as a result of a process of discussion among institutional actors in professional networks [14]. Bureaucratic cultures are characterized by regulation, rules, and consistency with standards related to regulatory bodies and external references such as institutional quality assurance procedures. Evaluation is based on the audit of procedures. Decision making is rule-based [9]. It is expected to work well in stable and centrally controlled organizations but can make a university resistant to change [15, p. 12]. Corporate cultures are characterized by an emphasis on loyalty to the department and its management. Management style is commanding and charismatic. There is a crisisdriven, competitive ethos. Decision-making is political and tactical. Evaluation is based on performance indicators and benchmarking [9]. Organizational culture is marked by the authority of the chief executive (the university ViceChancellor or President) and rigid institutional management and planning combined with devolution of responsibilities to the lower levels. Corporate culture is usually associated with transformational leadership and promotion of a collective identity [15, p. 12] Entrepreneurial cultures are characterized by a focus on competence and an orientation to the outside world, involving continuous learning in a turbulent context. The management style involves devolved and dispersed leadership. Decision-making is flexible and emphasizes accountable professional expertise. Its standards are related to market strength. Evaluation is based on achievement [9]. The focus here is on institutional change, adaptation and interaction with the environment [15, p.12].

Different modes of higher education governance have been present in different historical periods in higher education motivated by different forces and perceptions of the role of higher education in society. The concept of distributed leadership has been presented in the context of a shift in higher education institutions towards stakeholder organizations and would arguably equip universities with the flexibility and dynamics of creativity to respond to external demands in an environment of unpredictability. It is important to remind here that the classification presented by McNay are ideal types, i.e., models to which we compare reality but that do not necessarily correspond entirely to the reality. No university corresponds fully and exclusively to any of these models as these organizational cultures co-exist in most institutions but with different balances among them [13]. However, many studies of the shift over time from one organizational culture to another have identified the same sequence: from collegial to bureaucratic to corporate and finally to enterprise, involving first a tightening up on implementation, then a tightening up on goals and policy definition and finally a loosing up on control of implementation while retaining clear goals. It is important to have in mind here that, as an ideal model the present approach might incur in an oversimplification of the process of organizational change as there are different perceptions of these changes by different individuals within them.

Traditional collegial organizational structures and cultures, that are common in long-established, and sometimes medieval, research-intensive universities exhibit loose definition of policy and loose control over implementation, while enterprise cultures exhibit tight definition of policy and loose definition of implementation. Collective leadership is here thus identified with entrepreneurialism. Parston [16] defines the process of entrepreneurialism as managerial behavior which consistently exploits opportunities to deliver results beyond one's capabilities. Similarly, Thompson [17] argues that entrepreneurialism is about spotting and exploiting opportunities. According to this perspective an entrepreneur individual or an entrepreneur organization is one with a vision, who spots a new opportunity and is minded to act on it and start something. Slaughter and Leslie [18, p.114] present an operational definition of entrepreneurial activities in higher education institutions as "activities undertaken with the view to capitalizing on university research or academic expertise through contracts or grants with business or with governmental agencies seeking solutions to specific public or commercial concerns". Although this operational definition seems to be an important tool to identify some of the entrepreneurial activities developed by university units, it is not sufficient to understand broad institutional changes. Moreover, Clark [19, p. 5] applies the concept of entrepreneurialism as characteristic of social systems, i.e., of entire universities and their internal departments, research centers and schools. According to his definition, an entrepreneurial university "actively seeks to innovate in how it goes about its business. It seeks to work out a substantial shift in organizational character so as to arrive at a more promising posture for the future (..) Institutional entrepreneurship can be seen as both process and outcome" $[19$, p. 4]. In this process whose outcomes are unknown, risk is allegedly always a major factor. Distributed leadership has thus been presented as a response to uncertainty as it is expected to provide higher education institutions with the organizational capacity to operate in a constantly changing environment. The view of leadership that is being presented is intrinsically an instrumental one.

Different interpretations of changes in higher education illustrate that different organizational cultures are not necessarily mutually exclusive $[12,17]$. Aspects of collegial, managerial and corporate decision-making may often be copresent and accommodated with entrepreneurial principles. However, the promotion of distributed leadership is more part of the set of organizational values of the entrepreneurial model than of other models. It is important to discuss here collegiality in the light of distributed leadership and entrepreneurialism in higher education.

\section{COLLEGIALITY}

The strengthening of professional managerial expertise in universities leads to a discussion about the role of collegiality in the new university. A more succinct definition of collegiality states that it is a principle of professional selfregulation [20]. Part of the literature about higher education presents a discourse of nostalgia and golden ageism by describing that current arrangement for quality assurance are in opposition to traditional collegiate practices for managing academy [21, p.107). Some authors understand that current changes in management practices in higher education have resulted in a process of "loss of collegiality". In the year 2000, when distributed leadership had not yet become a fashionable term and the discussion about changes in higher education was focused the dangers of managerialism, Knight 
and Trowler [22, p. 72] described processes of loss of collegiality marked by less time to socialize due to "hard managerialism". Hargreaves [23] describes the rise of a contrived collegiality which is defined as administratively regulated, compulsory, fixed in time and space and predictable. However, other authors suggest a redefinition of collegiality in the modern university. Middlehurst [24] argues that collegiality in the new university should be reconceptualized as the sharing of information, ideas and tasks. Clark [25] presents a broader reconceptualization of collegiality in modern higher education as the coparticipation of academics and managers in decision-making towards a mixture of collegial and bureaucratic managerial cultural. Thus, collegiality appears to be interrelated with bureaucracy and not longer disconnected with the organizational hierarchies of the entrepreneurial university. As this perspective integrates universities with wider public policy reforms, collegiality is no longer seen as defensive ideology against change, but as one that reinforces change [6, p. 14]. The university in this model is allegedly one innovative and able to respond to change and to adapt to external demands. This model emphasizes the role of academic units as sources of innovations:

for change to take hold, one department after another needs itself to become an entrepreneurial unit, reaching more strongly to the outside with new programs and relationships and promoting third-streams income. Their members need to participate in a managerial line that stretches from central officials to heads of departments and research centers $[19$, p. 7]

To what extent this model is in fact being implemented and if it really delivers what it promises when Clark [25, p. 23] claims that it "maintains continuity with the past and present (...) provides new foundations for the rebuilding of internal collegiality and external autonomy" still remains to be seen and will probably continue to be a highly contested topic. It is fundamental to discuss distributed leadership and the role of departmental leadership against a backdrop of an ideal of entrepreneurialism in higher education.

\section{DEPARTMENTAL LEADERSHIP AND FORMS OF DISTRIBUTED LEADERSHIP}

One way of understanding institutional changes in universities is to look at systems of work relations which are most significantly present at the departmental level. In a higher education institution, the academic department or subunit of it is usually the main activity system for most academic staff [26]. Especially in large research-intensive universities with relatively highly loosely coupled structures, academic departments and subunits becomes the main focus of analysis in order to understand change. Some studies report that faculty members have a strong commitment to their discipline, which often overshadows loyalty to the university [23]. Bolden et al.'s [27, p. 10] focused their study on leadership at the department level assuming that "this is the main operational unit of universities, the primary source of future senior academic leaders, and the main point of interface between leadership of the institution and leadership of the academic discipline". Therefore, university academic departments and working relations within those are interesting areas to investigate how leadership is perceived and, to what extent distributed leadership is present. Gronn [28, p. 429] operationalizes the concept of distributed leadership with perspective on processes by presenting distributed leadership as "concertive action" which means to act together by mutual agreement. Here the focus is not on the agency of individuals but on structurally cojoint agency performed by a plurality of independent organization members. Concertive action is suggested in opposition to "numerical action" which understands distributed leadership as "the aggregated leadership of an organization is dispersed among some, many, or maybe all of the members" [28, p. 429]. He presents three forms of concertive action attributed with leadership:

\section{- $\quad$ Spontaneous collaboration}

This form assumes that leadership is regularly evident in the interaction of leaders (both formal and nonformal) in a way that their practice is extended over the social and situational contextual of the organization.

\section{- $\quad$ Intuitive working relations}

Here, understandings are known to emerge over time when individuals trust each other and develop a close working relationship. Thus, leadership is expected to be manifested in the shared role space covered by their partnership.

\section{- $\quad$ Institutionalized practices}

It can be seen as the tendency to institutionalize formal structures and it is observed when it is seen as inappropriate for a sole individual to be in charge. Gronn [28] observes that distributed leadership often begins spontaneously, or intuitively, in an organization but goes on to become institutionalized.

When empirically researching distributed leadership, the units of analysis should be these three forms of concertive action rather than individual choices or interpersonal relations. Gronn also identifies two properties of distributed leadership: interdependence and coordination. Interdependence is manifested in two ways: by the overlapping of member's responsibilities and also by these responsibilities being complementary. Coordination involves the managing of dependencies to ensure that people and resources are all coordinated to achieve the required performance. The unit of analysis suggested by Gronn can frame the study if the research objective is to identify distributed leadership. However, it is important to give space to respondents to spontaneously present and frame their own understandings and perceptions of leadership. A central paradox in this field is that although distributed leadership emphasizes collective action rather than formal leaders' individual action, most research that has been conducted so far in higher education draw conclusions almost only from interviews with individuals in formal academic or administrative posts. The lack of observational data probably in most of these studies also hinders the ability to draw more conclusive assertions in regard to work relations in academic environments. 
Are these expected characteristics of distributed leadership compatible with academic institutions where individual autonomy provides members with the authority to decide how they conduct their career with relative little interference from peers or external agents? Is it likely to flourish in academic departments where reward, recognition and career paths tend to reward individual over collective achievement [27]? If it really happens, it seems to be fair to incur that there is a shift in power from the individual academic to the collective. A collective that is part of an organization situated in a context of external competition for resources and recognition. These questions have to be discussed in the backdrop of a shift in institutional changes in higher education organizations from autonomous collectivities to stakeholder organizations. Leadership needs to be discussed in the context of such institutional changes.

\section{LEADERSHIP AND INSTITUTIONAL CHANGES}

I assume here that current changes in higher education occur in response to external factors rather than being caused by institutions' internal motivations. Clark [29] identifies four major factors affecting academic behavior and culture: the discipline, the higher education institution, the national system and the academic profession. On his turn, Maassen [30] has identified these as institutional contexts that, with the exception of the discipline, can be directly influenced by external actors. Thus, in order to understand such changes it is necessary to look at the interaction between external demands and higher education institutions internal dynamics [31, 32]. Leadership is related with this interaction as it reflects processes of adaptation of the organization to internal values and external demands. In this context, as Bleiklie [31, p. 191] claims, it would be a misconception to translate institutional success by organizational achievement: "whilst an organization such as a university may grow and become more secure if it is efficiently managed, it may nevertheless 'fail dismally' if it is led by administrators without a clear sense of values to be achieved". In environments of collegiality characterized by internal selfregulation, leadership tends to be a relatively fluid process as values seem to be accepted by the members. However, the need for leadership becomes more evident in times of organizational transformation when values are reconceptualized. It is the case of higher education institutions, as current transformations resulting from pressures to become more rapidly responsive to social and economical demands create an environment where collective and institutional autonomy are being delineated to respond to external demands. The claim for distributed leadership cannot be understood if taken away from institutional shifts and changes in power relations in higher education.

As Foucault [33, p. 208] stated, "a society without power relations can only be an abstraction. Which, be it said in passing, makes all the more politically necessary the analysis of power relations in a given society, their historical formation, the source of their strength or fragility, the conditions which are necessary to transform some and abolish others". At the same time that the discourse of accountability in higher education presents a democratizing rhetoric, it also emphasizes certain pedagogies and management processes in relation to others, being part of a move towards market values [21, p. 53]. A lack of awareness of political and economical aspects of accountability might limit our analysis by oversimplifying power relations in which leadership is embedded. In this sense, distributed leadership might have two different connotations. First, it can be a defensive discourse where traditional aspects of professional accountability to peers and self-organization are reinforced. On the other hand, it can also connote an adaptive response in terms of internal organization towards external pressures marked by processes where market accountability to customers is highlighted in relation to professional accountability. In other words, in the way that distributed leadership is being presented, there is nothing that indicates that power is also being distributed.

Distributed leadership presents a leadership discourse characterized by a democratizing discourse that emphasizes the importance of participation. It is sometimes presented as a defensive discourse in which traditional aspects of the collegial model of university leadership is reinforced. It is also sometimes promoted as an adaptive responsive strategy focusing on perceptions of external challenges in which marked accountability is strengthened. Arguebly, rather than the traditional leadership model of collegiality, distributed leadership would equip higher education institution with internal flexibility contributing to an organizational environment capable of operating creatively in an external environment of uncertainty and competitiveness. All in all, it is presented as a persuasive discourse that balances both principles of collegiality and management and thus internal and external values. However, the review of the literature showed a paradoxical situation in which distributed leadership has been characterized as a general organizational quality which instrumentally fulfills the need for efficiency and entrepreneurialism, but without exploring changes in institutional values and power relations.

\section{CONCLUSION}

Rather than focusing on organizational achievement, the goal of this paper was to discuss distributed leadership in the light of institutional change in higher education institutions. Mainly in the UK and in the US, distributed leadership has become a fashionable concept having already generated a considerable literature either descriptively or prescriptively presenting shared leadership. It brings a compelling discourse that aims at combining both principles of collegiality and management. However, the review of the literature suggests a paradoxical context where distributed leadership has been presented in higher education primarily as a claim for efficiency as a general organizational quality through an instrumental perspective rather than a set of institutional values. Supposedly, distributed leadership contributes to internal engagement and the strengthening of a sense of ownership in university affairs. However the lack of focus on power relations indicates that concertive action is not necessarily accompanied by distribution of power. For example, in the United Kingdom where the discussion about distributed leadership in education reform has had a relatively high impact, most universities are downsizing the committee structure which has historically been the formal system for bottom-up participation in the overall university decision-making [27]. Another limitation of the distributed leadership is that so far it has been "culturally-blind" by being an intrinsically Western concept with very little discussion about how it could be perceived or implemented in other contexts.

The concept has critical implications for organizational change and development that demand more empirical 
investigation. Interestingly, it does not deny the role of formal leaders but assumes that in entrepreneurial institutions, it consists in ensuring that other members can lead at certain times and have the necessary conditions to innovate and change. The most common misconception here is to identify distributed leadership with delegation of management activities. The concept of distributed leadership has a potential as an analytical framework as it draws attention to both vertical and horizontal dimensions of leadership and recognizes leadership outside lines of authority that are characteristic of formal hierarchies. However, in terms of its descriptive potential, further research on university dynamics and work relations is still needed to understand to what extent leadership practices and behaviors are really changing in higher education and how leadership is perceived among university members. The focus on perceptions of leadership in academic departments will certainly contribute to understand how and if collegiality might be assuming a different character and whether external values are being incorporated and balanced or accommodated with internal ones. In the overall sense, this is a discussion about perceptions of universities' values and mission.

\section{ACKNOWLEDGMENT}

None declared.

\section{CONFLICT OF INTEREST}

None declared.

\section{REFERENCES}

[1] Simkins T. Leadership in Education: "What works" and "what makes sense"? Educ Manage Admin Leadership 2005; 33(1): 9-26.

[2] Bryman A, Gillingwater D, McGuiness I. Leadership and organi-zation transformation. Int J Public Admin 1996; 19(6): 849-72.

[3] Grint K. Leadership: Limits and possibilities. Basingstoke: Palgrove Mascmillan 2005.

[4] Yukl G. Leadership in organizations. Upper Saddle River, NJ: Prentice Hall 2002.

[5] Fineman S, Sims D, Yiannis G. Organizing and organizations. London: Sage Publications Ltd. 2005.

[6] Bolden R, Gosling J, Dennison P. A review of leadership theory and competency frameworks. Edited version of a report for Chase Consulting and the Management Standards Centre 2003. Retrieved from the Centre of Leadership Studies - University of Exeter website: http://www.leadership-studies.com/documents/mgmt standards.pdf

[7] Azevedo C. Leadership and intersubjective process in health public organizations. Ciência, Saúde Coletiva 2002; 7(2): 349-61.

[8] Timperley H. Distributed leadership: developing theory from practice. J Curriculum Stud 2005; 37(4): 395-420.

[9] Gibbs G, Knapper C, Picinnin S. Departmental leadership for quality teaching - an international comparative study of effective practice (Final Report). Leadership Foundation in Higher Education; 2007. Retrieved from the Leadership Foundation In Higher Education website: http://www.lfhe.ac.uk/research/projects/gibbsoxford.html

[10] Bennett N, Wise C, Woods P, Harvey J. Distributed Leadership. A review of the literature carried for NSCL; 2003. Retrieved from the National College for School Leadership website: http://forms. ncsl.org.uk/mediastore/image2/bennett-distributed-leadership-full.pdf
[11] Bargh C, Scott P, Smith D. Governing universities: changing the culture?. Buckingham: SRHE and Open University Press 1996.

[12] Shattock M. Managing successful universities. Berkshire: Open University Press 2003.

[13] McNay I. From collegial academy to the corporate enterprise: The changing cultures of universities. In: Schuller T, Ed. The Changing University?. Buckingham: Open University/SRHE 1995; pp. 105-15.

[14] Miller H. The Management of change in Universities. Buckingham: SRHE and Open University Press 1995.

[15] Bolden R, Petrov G, Gosling J. Developing collective leadership in higher education Research report presented to the Leadership Foundation for Higher Education; 2007. Retrieved from the Leadership Foundation website: http://www.lfhe.ac.uk/protected/ bolden.pdf

[16] Parston G. Quoted by Leadbeater, C. \& Goss, S. Foreword. S. In Authors, Eds. Civic entrepreneurship. London: Demos/Public Management Foundation 1998.

[17] Thompson J. Fostering entrepreneurship and entreprise - the educationalists challenge. In: Fägerling I, Holmesland I, Strömqvist, G, Eds. Higher education at the crossroads: tradition or transformation? Stockholm: Institute for International Education 1999; pp. 43-262.

[18] Slaughter S, Leslie L. Academic capitalism. Politics, policies and the entrepreneurial university. Baltimore and London: John Hopkins University Press 1997.

[19] Clark B. Creating entrepreneurial universities: organizational pathways of transformation. Oxford: Pergamon Press 1998.

[20] Dill D. Through Deming's Eyes: a cross-national analysis of quality assurance policies in higher education. Quality High Educ 1995; 1(2): 95-110.

[21] Morley L. Quality and power in higher education. Berkshire: Open University Press 2003.

[22] Knight P, Trowler P. Departmental-level cultures and the improvement of learning and teaching. Stud High Educ 2000; 25(1): 69-83.

[23] Hargreaves A. Changing teachers, changing times: Teachers' work and culture in the postmodern age. London: Cassell 1994

[24] Middlehurst R. Leading academics. Buckingham: Open University Press 1993

[25] Clark B. The entrepreneurial university: new foundations for collegiality, autonomy and achievement. Higher Educ Manage 2001; 13(2): 9-24

[26] Becher T, Trowler P. Academic tribes and territories. Milton Keynes: Open University Press 2001.

[27] Bolden R, Petrov G, Gosling J. Developing collective leadership in higher education. final report for the leadership foundation for higher education 2007

[28] Gronn P. Distributed as unit of analysis. Leadership Q 2002; 13(4): 423-51.

[29] Clark B. The higher education system. academic organization in crossnational perspective. Berkeley: University of California Press 1983.

[30] Maassen P. Government steering and academic culture. The intangibility of the human factor in Dutch and German universities. Utrecht: De Tijdstroom 1996.

[31] Bleiklie I. Academic leadership and emerging knowledge regimes. In Bleiklie I, Henke M. Eds. Governing Knowledge. A study of continuity and change in higher education. A festschrift in honour of Maurice Kogan. Dordrecht: Springer 2005; pp. 189-211.

[32] Maassen P, Gornitzka $\AA$. Integrating two theoretical perspectives on organizational perspective. In: Jongbloed B, Maassen P, Neave G, Eds. From the eye of the storm: higher education's changing institution. Dordrecht: Kluwer Academics \& CHEPS 1999; pp. 295-313.

[33] Foucault M. The Subject and Power. In: Dreyfus H, Rabinow P, Eds. Michel Foucault beyond Structuralism and Hermeneutics. Chicago: University of Chicago Press 1982; pp. 208-26.

This is an open access article licensed under the terms of the Creative Commons Attribution Non-Commercial License (http://creativecommons.org/licenses/by-nc/ 3.0/) which permits unrestricted, non-commercial use, distribution and reproduction in any medium, provided the work is properly cited. 